\title{
Evaluation of Copper Stave Remnant Thickness in Blast Furnace Using Ultrasonic Method
}

\author{
Sriniwasagan BALAMURUGAN,${ }^{1{ }^{*}}$ Rajendran SHUNMUGASUNDARAM, ${ }^{1)}$ Mantu PATRA, ${ }^{2)}$ Sameeran PANI ${ }^{2)}$ \\ and Monojit DUTTA ${ }^{11}$
}

1) Research \& Development, TATA Steel, Jamshedpur-831001, Jharkhand, India.

2) H-Blast Furnace, TATA Steel, Jamshedpur-831001, Jharkhand, India.

(Received on September 6, 2014; accepted on November 25, 2014)

\begin{abstract}
Blast furnace is one of the most important parts in an integrated iron and steel industry where smelting of iron is carried out. Staves are essential part of a blast furnace, which increase blast furnace campaign life by providing cooling in order to protect the external steel shell from heat as well as to maintain the inner profile of the blast furnace. Under high temperature environment, stave wear takes place due to downward and upward motion of materials and hot gases, respectively. Thickness of the stave should be monitored on a continuous basis to prevent any catastrophic failure. In this study an ultrasonic test method was adopted to carry out the thickness measurement of copper staves. Measuring copper stave thickness involves two challenges; direct accessibility from the outside and its inherent intricate geometry. In this paper, a complete methodology comprising ultrasonic sensor and fixture mechanism to overcome the above challenges is discussed. An innovative stave thickness measuring device was first developed and calibrated in the laboratory, which was then used to measure the remnant stave thickness of a running industrial blast furnace. The results were verified by hole drilling method that proved the developed methodology as a reliable one.
\end{abstract}

KEY WORDS: blast furnace; copper stave; ultrasonic test; sensor fixture.

\section{Introduction}

Blast furnace consists of an enclosed space or shaft for reducing and melting materials, and a cylindrical chamber for collecting molten metal. It is used to make iron from iron ore. Sized coke, iron ore and sintered ore are charged into the blast furnace and hot air is supplied through tuyers. Eventually molten iron is obtained after the reaction in the chamber. ${ }^{1)}$ An effective furnace shell cooling is must for a long campaign life. Copper cooling boxes, cast-iron staves as well as spray cooling or double jacket cooling for the hearth walls are typical examples of the cooling system in blast furnaces. The recent development for the cooling of a blast furnace is copper staves. ${ }^{2)}$ They are stacked at four levels B1, B2, S1 and S2 inside the blast furnace above tuyers as shown in Fig. 1.

Each level has 48 staves. Each stave has four inlet and outlet cooling channels to take away the heat from hot metal in order to protect shell of the blast furnace. These channels were drilled and its ends were plugged. Cooling pipes were welded with cooling channels. As shown in Fig. 2, inner face of the stave has thick and thin section alternatively.

Copper staves are with inlet and outlet ports to circulate water through them. Water that enters through inlet is guided to flow in vertical cooling channel and as it is passing, it

* Corresponding author: E-mail: balasndt@gmail.com DOI: http://dx.doi.org/10.2355/isijinternational.55.605

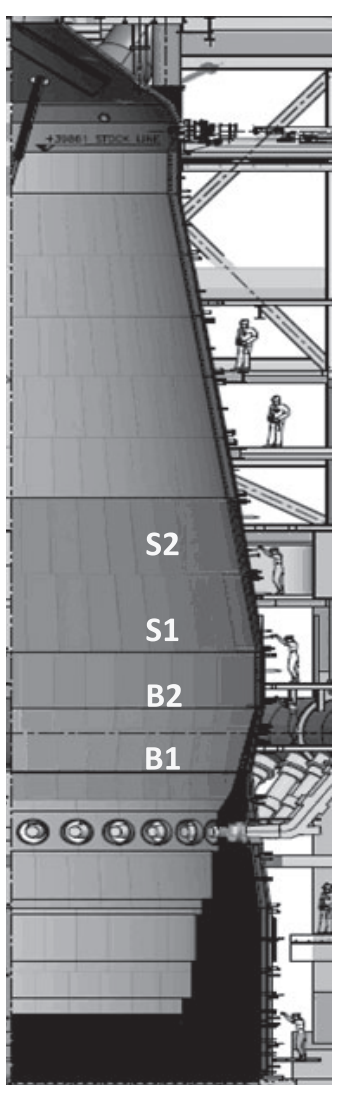

Fig. 1. Half sectional view of blast furnace. 


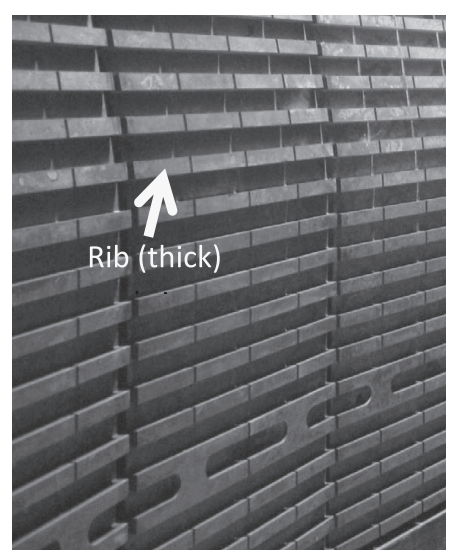

Fig. 2. Copper stave.

takes away heat from the copper stave, which is exposed to elevated temperature. Based on the blast furnace design, copper staves will be installed in a particular orientation to the molten metal flowing direction at different elevations. Copper stave orientation and the molten metal temperature highly influence the wear in the copper stave. Inner face of the copper stave has ribs like structure as shown in Fig. 2. As mentioned above these thicker portions (rib) are vulnerable to wear, since they are more exposed to sliding molten metal compared to the thinner portion. Thickness of the cooling stave should be tracked on a regular basis to prevent massive water ingression leading to catastrophic failure of the furnace, which can occur at the worst wear condition.

As the staves are located inside the shell, one side of the stave is accessible through cooling pipes during shut down. Ultrasonic based thickness measurement is the most appropriate technique for thickness measurement of the one side accessible objects. Object thickness can be determined based on transit time measurement $(\mathrm{t})$ of ultrasonic wave in the material. If sound velocity in the material is known, then thickness can be calculated using the following Equation. ${ }^{3)}$

$$
T=\frac{c^{*} t}{2}
$$

$\mathrm{T}=$ Thickness (mm)

$\mathrm{c}=$ Velocity of ultrasound $(\mathrm{mm} / \mathrm{s})$

$\mathrm{t}=$ Transit time of ultrasound $(\mathrm{s})$

There are two challenges involved to employ the above ultrasonic technique for measuring stave thickness; direct accessibility from outside and its inherent intricate geometry. These two challenges are to be tackled to measure the remnant thickness of the copper stave and also to monitor the damage level of the same. More importantly the technique should be free from faulty measurement, since an inaccurate measurement can lead to catastrophic failure of the blast furnace or otherwise unplanned shutdown which will affect the production dramatically. Thus a proper measurement technique plays a crucial role in determining blast furnace campaign life.

In our work, a suitable fixture along with guide blocks was developed to address the first challenge. A reference block was also made which replicates the stave with all its intricate geometries and also simulates different stave conditions. The block was used as the reference while optimizing the sensor characteristics as well as fixture design to overcome the second challenge.

In this paper, a complete methodology of measuring the remnant thickness of a blast furnace stave along with the details of fixture, guide block design and sensor has been discussed in details. Plant trial results are also presented with detailed interpretation.

\section{Methodology}

Ultrasonic based thickness measurement technique is the appropriate non-destructive technique for measuring remnant thickness, where only one side is accessible, because the other NDT methods such as X-ray, microwave have constraints to access the copper staves. ${ }^{4)}$ Conventional ultrasonic testing is adopted here for measuring stave thickness. This technique demands proper contact of the sensor with test surface, which is quite difficult in this case as the staves are located inside the blast furnace. A fixture with guiding mechanism was therefore developed to carry the ultrasonic sensor up to stave through cooling ports. Reference block was also made to simulate various plant conditions. As explained in Fig. 3, the measurement methodology includes calibration and verification of the probe and fixture at laboratory using the reference block. Different thicknesses were measured and based on these test results fine tuning of the fixture was done. Finally, the fine-tuned testing set-up was taken for plant trials.

\section{Designing the Measuring Set-up}

The measuring set-up consists probe and fixture, guide blocks and reference block. The design of all the measuring set-up is discussed in this section.

\subsection{Design of Fixture and Guide Block}

Basic function of a fixture is to carry the ultrasonic sensor up to stave cooling channel and ensuring proper contact with the channel wall. Design of the fixture depends on few important stave design parameters. Schematic drawing of a typical copper stave cross section is shown in Fig. 4. Here $\mathrm{X}$ is inner dia. of the pipe provided for water circulation, $\mathrm{Y}$ denotes the minimum length that is needed to reach the inner wall of the cooling channel and $\mathrm{Z}$ is the down height from pipe centre axis to centre of the rib. $\mathrm{R}$ is the diameter of the cooling channel.

While designing the fixture, above dimensions are the constraints within which the task of measuring remnant thickness of the copper stave should be achieved. Sensor fixture should be longer than the minimum length (Y), so that the ultrasonic sensor can be pushed on to cooling channel inner wall from outside during measurement. Secondly the thick section of the stave is away from pipe centre axis by $\mathrm{Z} \mathrm{mm}$, so the sensor should be fixed in the fixture at $\mathrm{Z}$ $\mathrm{mm}$ down as shown in Fig. 5 and at the same time $Z$ should not be greater than X, otherwise the fixture cannot be inserted through the cooling pipe at all. Also optimal sensor diameter should be selected based on cooling channel diameter, $\mathrm{R}$.

According to different ports in different staves B1, B2, S1 and S2, fixture dimensions were calculated and tabulated in Table 1. 


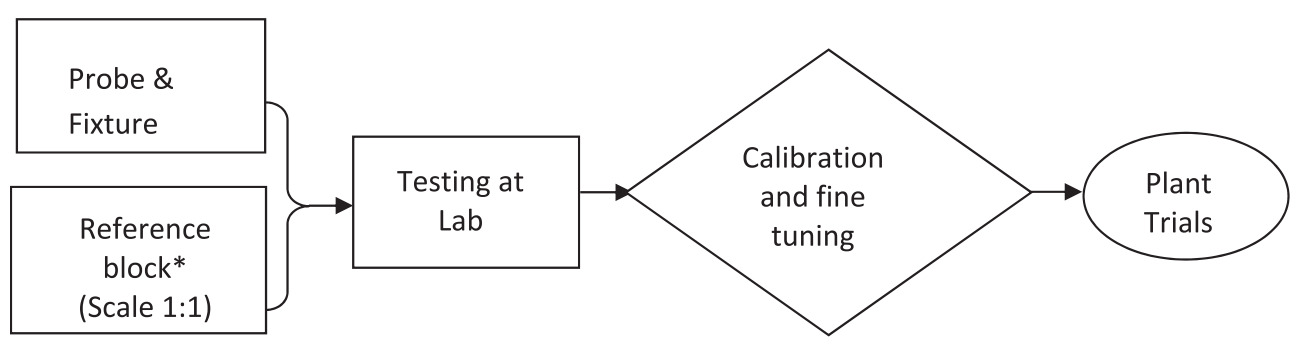

* Reference block simulates different plant conditions

Fig. 3. Methodology for stave thickness measurement.

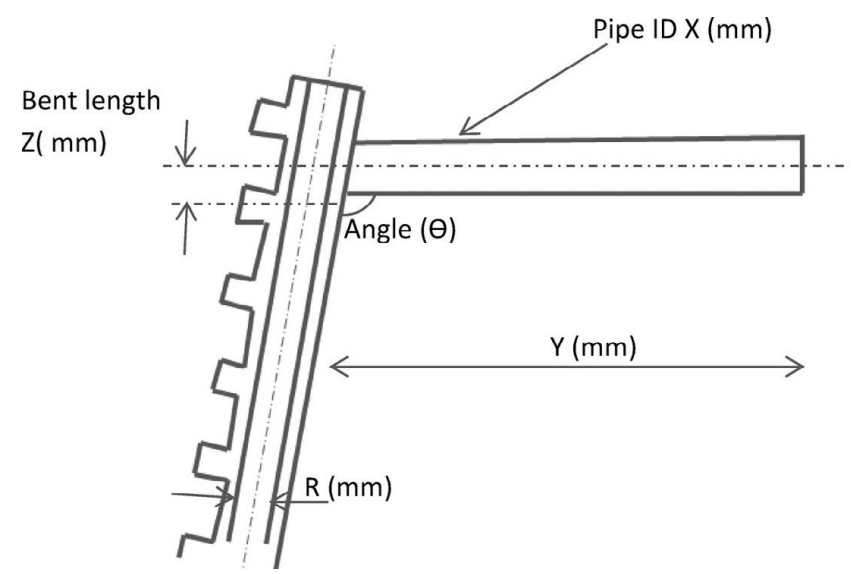

Fig. 4. Schematic drawing of copper stave cross sction.

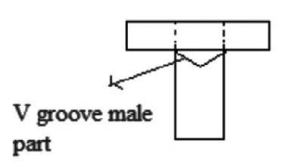

End view

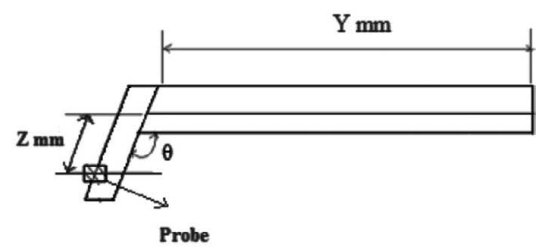

Elevation View
Fig. 5. Schematic drawing of sensor fixture.

Table 1. Dimensions of staves considered during fixture design.

\begin{tabular}{cccccc}
\hline $\begin{array}{c}\text { Dimensions of } \\
\text { different staves }\end{array}$ & $\begin{array}{c}\text { B1 } \\
\text { Bottom }\end{array}$ & $\begin{array}{c}\text { B1 Top, } \\
\text { B2 Bottom }\end{array}$ & $\begin{array}{c}\text { B2 } \\
\text { Top }\end{array}$ & $\begin{array}{c}\text { S1 } \\
\text { Bottom }\end{array}$ & $\begin{array}{c}\text { S1 Top, } \\
\text { S2 Bottom } \\
\text { \& S2 Top }\end{array}$ \\
\hline Length Y mm & 700 & 700 & 700 & 700 & 700 \\
Pipe Dia. X mm & 55 & 55 & 55 & 55 & 55 \\
Angle $\theta\left(^{\circ}\right)$ & 93 & 99 & 90 & 81 & 99 \\
Bent Length Z mm & 35 & 30 & 40 & 30 & 35 \\
\hline
\end{tabular}

While handling the sensor from outside, there are possibilities for fixture to get tilted. This will lead to improper contact of the sensor with cooling channel. To avoid sensor getting tilted, a guide block was designed as shown in Fig. 6. Guide block diameter matches with inner diameter of the pipe, and a $\mathrm{V}$ groove is made in the guide block. Fixture was given male part of the $\mathrm{V}$ groove as shown in Fig. 5, so that during testing the fixture will be seated on the guide block and the $\mathrm{V}$ groove in the guide block will restrict the fixture movement in circumferential direction. Hence the $\mathrm{V}$ groove

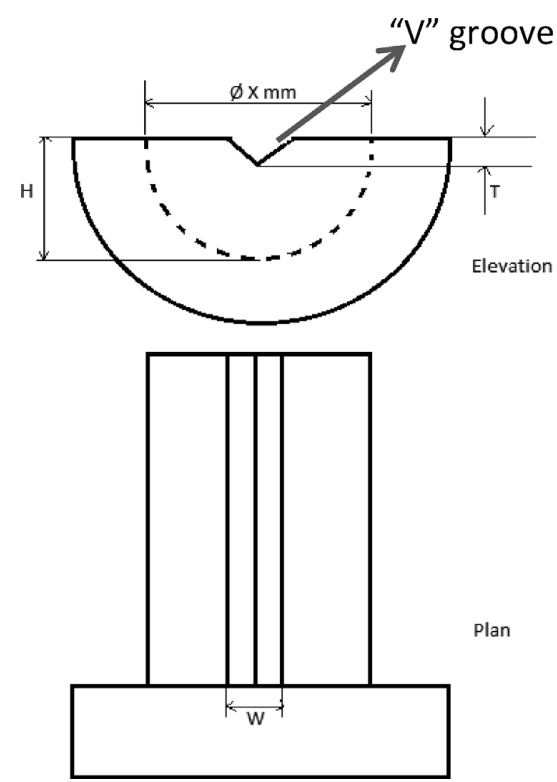

Fig. 6. Guide block - 1 with height $\mathrm{H} \mathrm{mm}$.

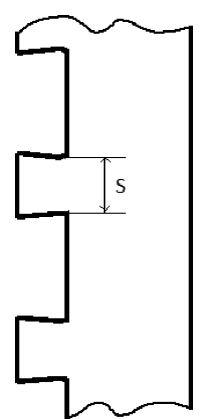

Fig. 7. Copper stave end view showing rib width.

avoids sensor getting tilted. In Fig. 7 the end view of the copper stave rib portion is shown.

As shown in Figs. 8 and 9, guide blocks have been made in three different heights: $\mathrm{H}, \mathrm{H}-0.6 \mathrm{~S}$ and $\mathrm{H}+0.6 \mathrm{~S}$, Where $\mathrm{H}$ and $\mathrm{S}$ are the radius of the inlet pipe and width of the rib, respectively, to assure the measurement has been taken at thick section of the stave. As the guide blocks are in 3 different, it will move the fixture vertically without affecting sensor alignment. For instance, while the fixture with guide block-1 makes the sensor to measure thickness at centre of rib portion, then fixture with guide block- 2 and 3 will measure thickness from less thickness portion, because height 


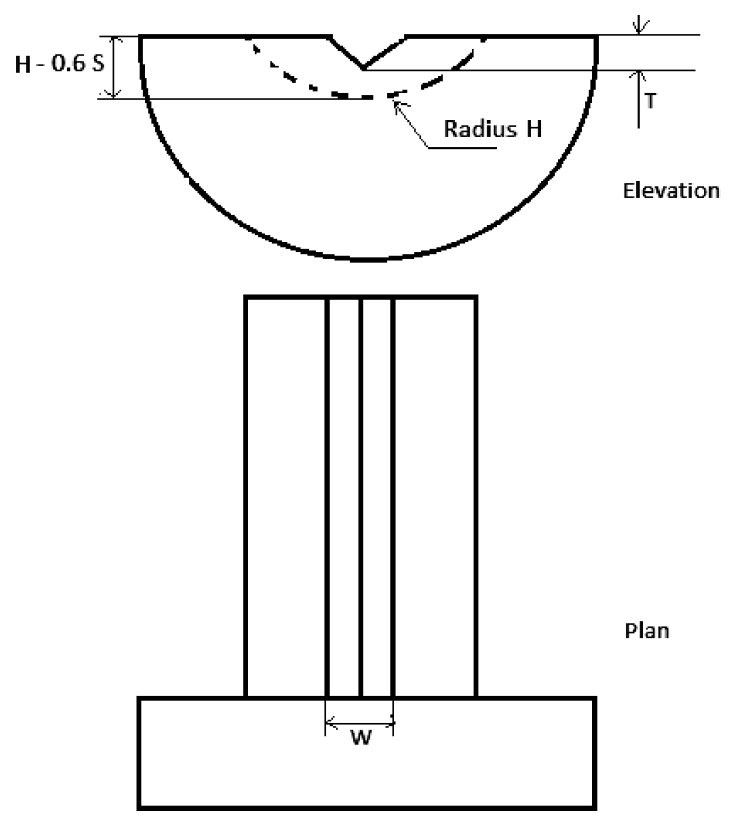

Fig. 8. Guide block -2 with height of $\mathrm{H}-0.6 \mathrm{~S} \mathrm{~mm}$.

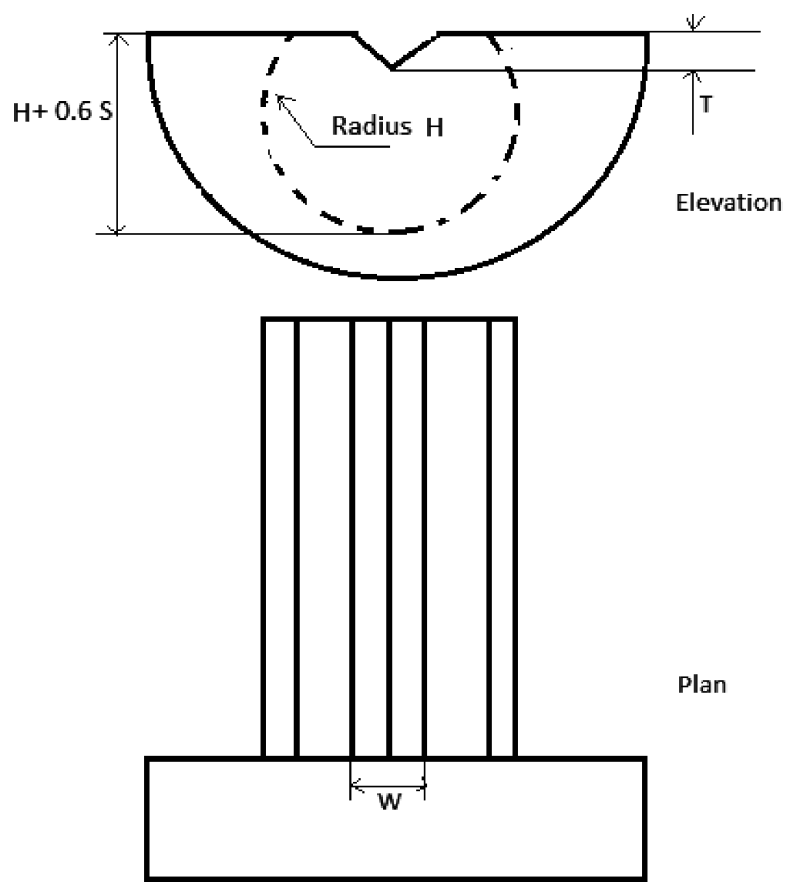

Fig. 9. Guide block- 3 with height of $\mathrm{H}+0.6 \mathrm{~S}$.

variation in the guide block shifts the sensor away from the rib. Total height variation in the guide block is 1.2 times of $\mathrm{S}$ that is greater than the width of rib portion. Greatest thickness measured by this method with two guide blocks should represent the thickness of rib portion.

\subsection{Design of Reference Block}

The intention of making reference block of same material in full scale was to optimise the ultrasonic sensor characteristics as well as to calibrate the entire system. The block was made of rolled copper blank, machined and drilled according to the original stave design. The block with cooling pipe possesses the actual challenges that a real copper stave produces for carrying out ultrasonic testing. It incorporates dif-

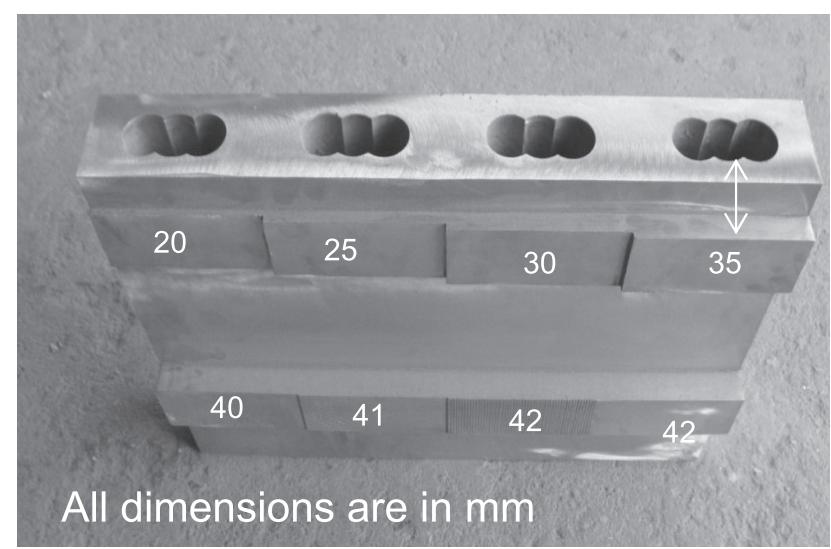

Fig. 10. Reference block.

ferent conditions of original copper stave; different rib thicknesses $(42,41,40,35,30,25$ and $20 \mathrm{~mm})$ and also rough surface in rib portion. All dimensions of the reference block were designed as per original copper stave drawing. The cooling pipe was joined with cooling channels in the block by threading in order to remove the pipe for measuring the various thicknesses. Figure 10 shows the reference block for copper stave thickness measurement.

\section{Experimental Details}

Ultrasonic flaw detector equipment (EPOCH 4, M/s Olympus NDT) was used for measuring different known thicknesses of the reference block by gating method, where the position of the back wall echo will be determined by a gate. Ultrasonic Transmitter - Receiver (T/R) sensor was selected as it is appropriate for thickness measurement, however the frequency is one of the important criteria which will affect testing performance. The frequency of ultrasonic wave determines the measurement sensitivity because sensitivity and frequency are in direct relationship. But the limitation is the maximum thickness the wave can travel which is inversely proportional to frequency. By considering the above fact, $4 \mathrm{MHz}$ Transmitter - Receiver (T/R) sensor was selected. The advantage of using $4 \mathrm{MHz}$ frequency is low beam off setting angle in the far field region. Low beam offset is desired to avoid beam diffractions at the corners of the thick and thin sections, which can cause erroneous result. Because of the curvature sensor size should not be more to obtain flat seating of the sensor, at the same time if the sensor size is too low then beam off set angle will increase as given in Eq. (2). ${ }^{3)}$ Hence optimal size $8 \mathrm{~mm}$ was selected by considering flat seating of the sensor and reducing beam offset. The sensor was fixed with the fixture as shown in Fig. 11. Cooling pipe was carefully fixed with reference block before taking measurement.

$$
\phi=\sin ^{-1} \frac{v}{d f}
$$

Where $\phi$ - Beam off setting angle $\left(^{\circ}\right)$,

$v$ - Sound wave velocity $(\mathrm{m} / \mathrm{s})$

$d$ - Diameter of the sensor $(\mathrm{mm})$,

$f$ - Frequency of the wave $(\mathrm{MHz})$.

The fixture was inserted through the cooling pipe and its alignment with the axis of the pipe was ensured by using the 


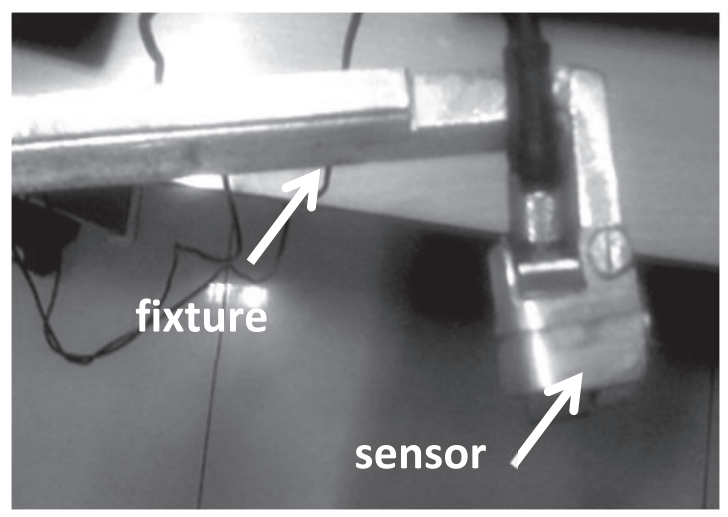

Fig. 11. Sensor with fixture.

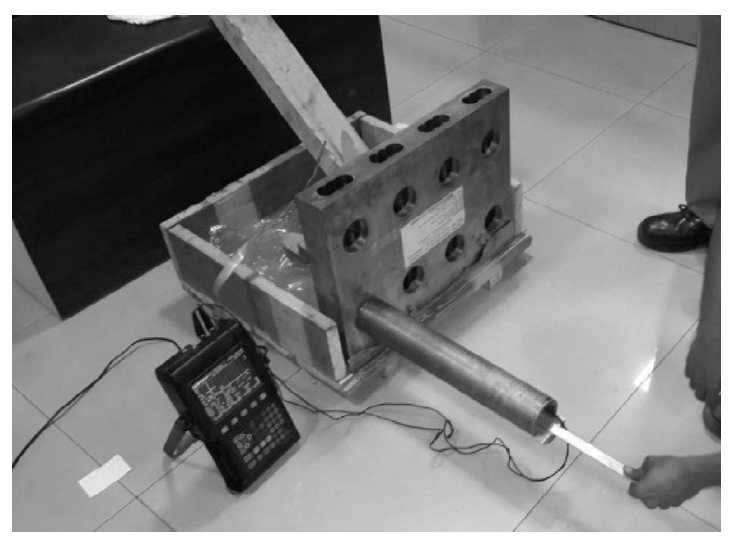

Fig. 12. Lab scale setup.

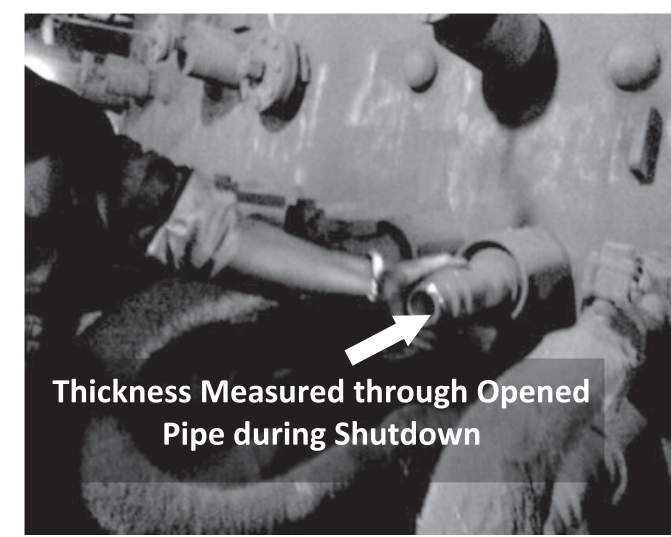

Fig. 13. Cooling channel opened for inserting fixture.

guide block 1, 2 and 3. During measurement $100 \mathrm{~mm}$ thickness range was set in the equipment and thick couplant was applied, since the testing surface has radius of curvature. Figure 12 shows the lab scale set up for thickness measurement.

Based on lab scale experiments, the whole set-up was calibrated and taken to the blast furnace during shutdown for measuring the copper stave thickness. Prior to measurements, the cooling channel was opened as shown in Fig. 13 for inserting the fixture. After draining water, the sensor and fixture set-up was inserted through the opened pipe and placed properly with the help of guide block. The ultrasonic flaw detector equipment (EPOCH 4) was used for measuring the thickness. After measurements the cooling channel
Table 2. Lab scale measurements.

\begin{tabular}{cccc}
\hline S1 No & $\begin{array}{c}\text { Actual } \\
\text { Thickness }(\mathrm{mm})\end{array}$ & $\begin{array}{c}\text { Measured } \\
\text { Thickness }(\mathrm{mm})\end{array}$ & Error (mm) \\
\hline 1 & 20 & 19.03 & -0.97 \\
2 & 25 & 25.14 & 0.14 \\
3 & 30 & 30.62 & 0.62 \\
4 & 35 & 34.9 & -0.1 \\
5 & 40 & 40.02 & 0.02 \\
6 & 41 & 41.23 & 0.23 \\
7 & 42 & 41.97 & -0.03 \\
8 & 42 (rough surface) & 43.02 & 1.02 \\
\hline
\end{tabular}

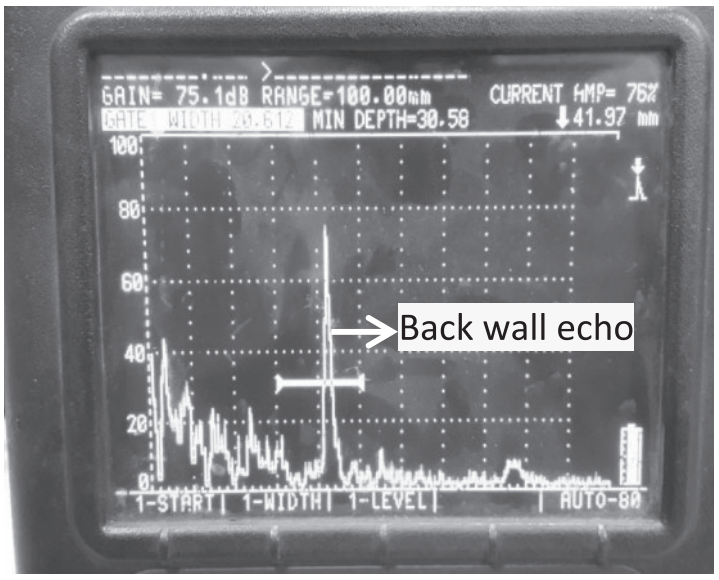

Fig. 14. Lab scale testing result.

was carefully closed and water circulation was started. In addition to the ultrasonic measurement, hole drilling method was performed for verifying the results. In hole drilling method a copper rod was inserted through inspection bolt till other end of stave surface and remnant length of the rod will be measured during every shut down. The remnant length represents the thickness of the stave.

\section{Results and Discussion}

As mentioned in the experimental section, different thicknesses of thick section of the reference block were measured using guide block-1 as tabulated in Table 2. The maximum error in the measurement was found to be $1.02 \mathrm{~mm}$, which is the random error as per standard. ${ }^{5)}$ A typical measurement display has been shown in Fig. 14. Despite of Transmitter/ Receiver sensor usage, initial echo was found which was caused by thick couplant and since it was within $20 \mathrm{~mm}$, measurement was unambiguous. The gain energy was set at $75.1 \mathrm{~dB}$ for getting initial back wall which represents known thickness of the reference block. Then the same measurement was carried out using guide block- 2 which enables thickness measurement of thin section of reference block. Thus the measurement was done at thick and thin section of the reference block.

During shutdown of the blast furnace, remnant thickness of the staves was measured at two places. Here the gain energy was set at $73.6 \mathrm{~dB}$ to measure the remnant thickness. Plant trial results are presented in Fig. 15. Back wall echo 


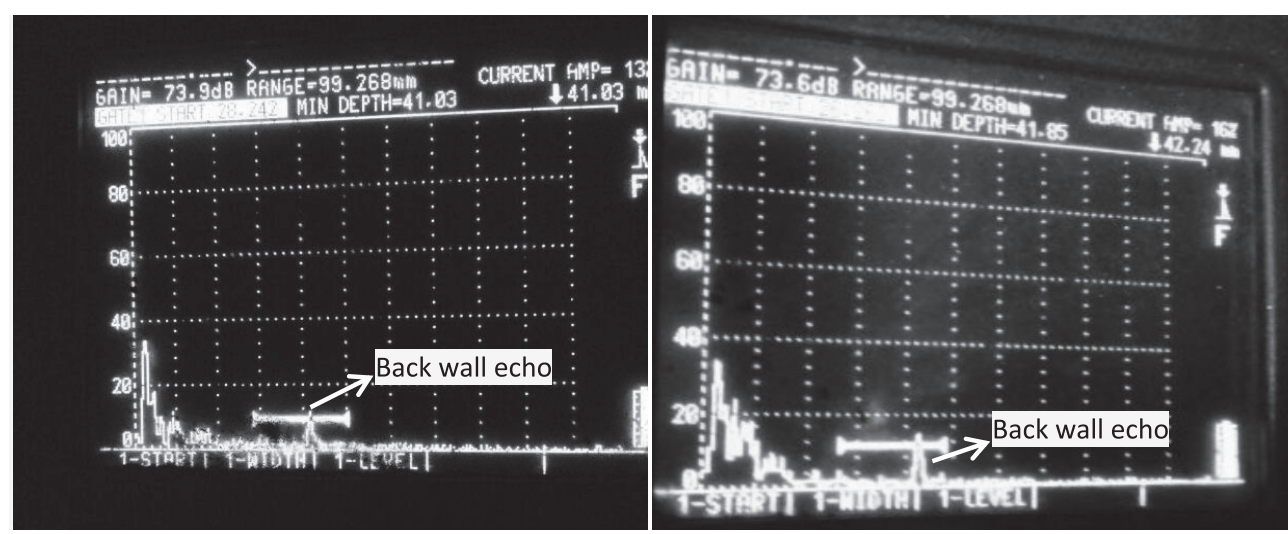

Fig. 15. Plant trial results measured through two different cooling pipes to measure local wear.

Table 3. Plant scale measurements.

\begin{tabular}{cccc}
\hline \multirow{2}{*}{ Position } & \multirow{2}{*}{$\begin{array}{c}\text { Design } \\
\text { Thickness (mm) }\end{array}$} & \multicolumn{2}{c}{ Measurement by } \\
\cline { 3 - 4 } & & Ultrasonic (mm) & Hole Drilling (mm) \\
\hline B1 Top- 40 & 42 & 41 & 41 \\
B1 Top - 32 & 42 & 42 & 39 \\
\hline
\end{tabular}

amplitude was not as high as it was in lab scale results although the gain was not changed much. It may be because of rough surface which could have scattered ultrasonic waves considerably. It eventually contributes the attenuation of ultrasonic wave. Plant trial results were verified by physical hole drilling method which is a full proof method for measuring the stave thickness. But it is not advisable to employ in the blast furnace as it is destructive. The comparison between the ultrasonic measurement results and hole drilling method is tabulated in Table 3. A maximum variation of $3 \mathrm{~mm}$ between hole drilling method and ultrasonic testing results was observed in thickness measurement. This variation could have been contributed by localized wear or due to the error involved in hole drilling method or combination of these two. As the maximum variation is only $3 \mathrm{~mm}$ compared with ultrasonic measurement, it is reasonable to state the ultrasonic based stave thickness measurement is a reliable method. There is very less possibility for fault indications during measurement because of $\mathrm{T} / \mathrm{R}$ sensor usage. Even in worst condition of staves inner profile due to operating conditions there will be chances only for no signal rather than fault signal.

\section{Conclusions}

A complete copper stave thickness measurement system based on ultrasonic method was developed which consists of sensor and fixture, guide blocks and reference block. Design of fixture and guide blocks, and appropriate sensor selection were discussed along with critical parameters which influences the testing result. The developed system was calibrated in lab scale using reference block and then the calibrated system was taken to blast furnace for actual stave thickness measurement. The plant trial results revealed only $1-2 \mathrm{~mm}$ of stave wear. To validate the results hole drilling method was carried out and the measured results were closely matching with ultrasonic results. Thus the system generates important information about the condition of the staves in order to achieve maximum campaign life of a blast furnace with safe operation practice.

\section{REFERENCES}

1) S.-W. Choi and D. Kim: AIP Conf. Proc., 1430, American Institute of Physics, USA, (2012), 1715.

2) H. BodoLuengen: AISTech Proc., Vol. 1, AIST, Warrendale, PA, (2011), 387.

3) J. Krautkraämer and H. Krautkraämer: Ultrasonic Testing of Materials 4th Fully Rev. ed., Springer-Verlag, Berlin, (1990).

4) J.-L. Yoo, T.-H. Choi and K.-T. Kim: Institute of Control, Robotics and Systems, Korea, (2010), 330.

5) ASTM Standard E-317 Standard Practice for Evaluating Performance Characteristics of Ultrasonic Pulse-Echo Testing Instruments and Systems without the Use of Electronic Measurement Instruments, ASTM International, USA, (2011). 